Historic, Archive Document

Do not assume content reflects current scientific knowledge, policies, or practices. 

Multiple use

merits your study and under-

THE NATIONAL FORESTS OF AMERICA

U.S. Department of Agriculture

Issued March 1961 


\section{multiple use}

is like your living room

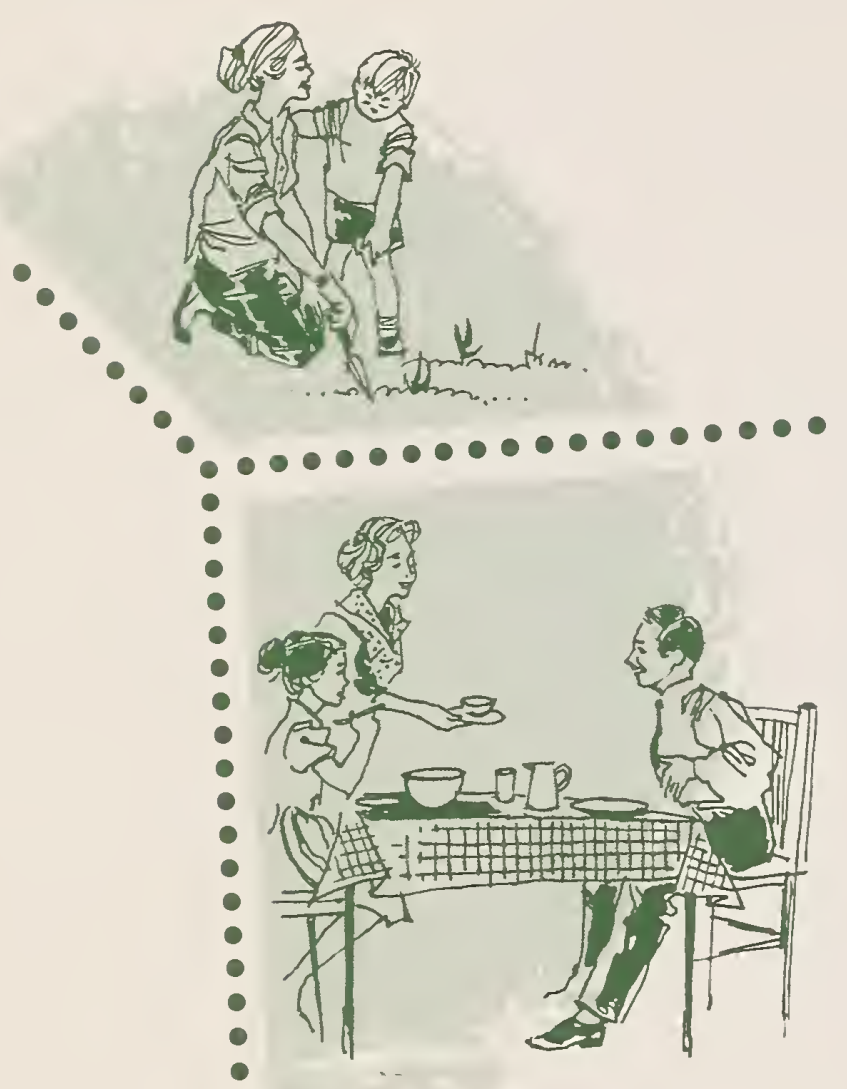

What is Multiple Use? Multiple Use of the forest might be compared to the many uses of the living room in your own home. The home has been used for generations in many different ways to benefit all members of the family. Births, weddings, parties, club meetings, and family meals are but a few of the activities centered around the home. Many different activities are centered also around the National Forests. These forest are run in much the same way as a household, but on a larger scale.

Father, mother, and the children are usually the members of the family living in the family home. Members of the National Forest family living in the forest are timber, water, wildlife, forage, and outdoor recreation. As in our own families, each member of the National Forest family is an important part of the group-something affecting one usually affects the others. The family suffers loss and is inconvenienced seriously if the family home is damaged or destroyed by fire. One or more members of the family may be injured and the others inconvenienced, if the family car is wrecked. Similarly, if timber is cut unwisely and the land stripped of cover and left bare, rain washes the topsoil, causing it to erode and fill streams with silt. This may kill fish, make the water unfit for human and animal consumption, and destroy scenic beauty. 


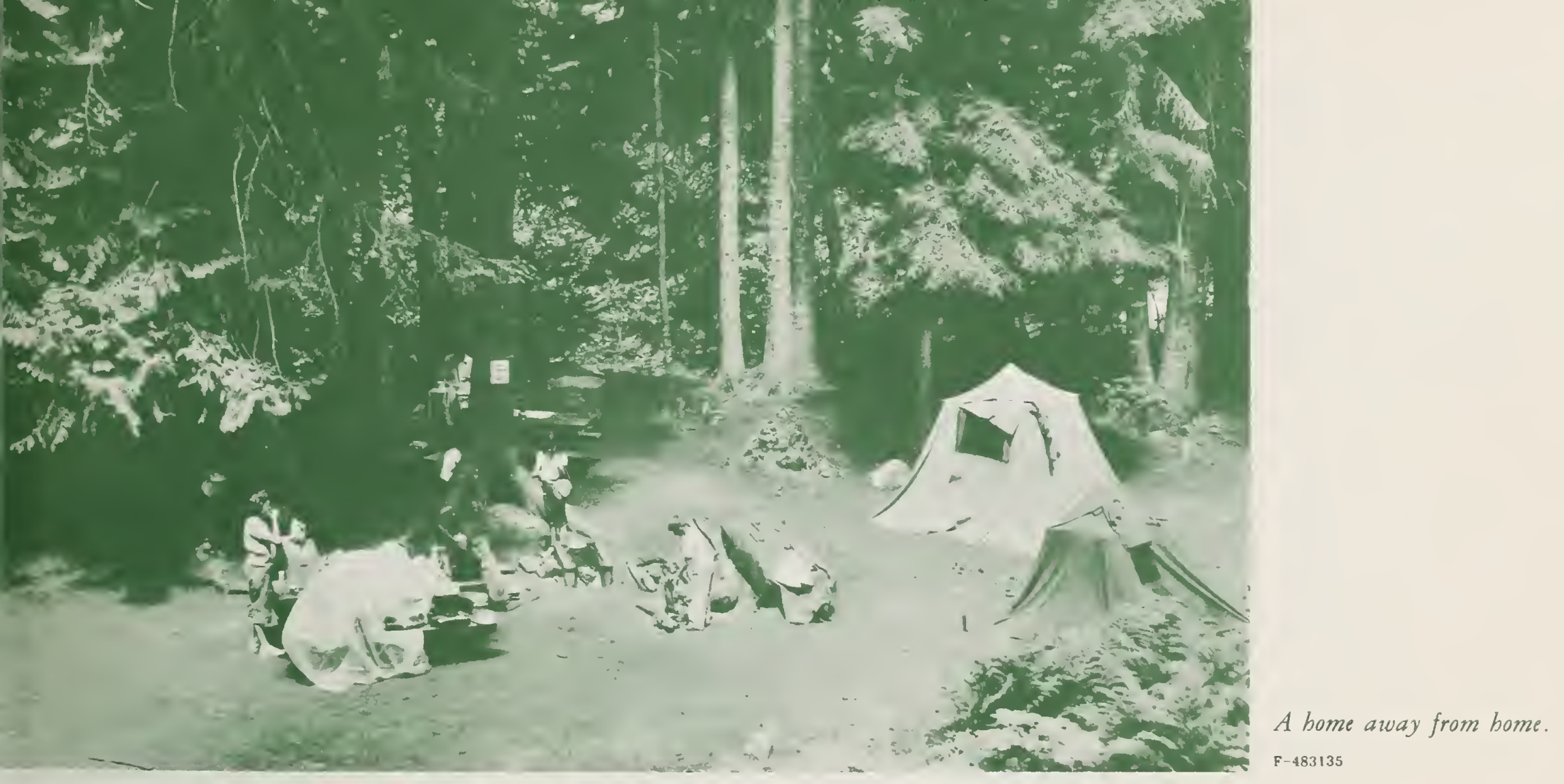


multiple use is balanced use

The Forest Service manages the National Forest resources to keep them in harmony with each other and in harmony with the needs of the people who use them. For example, in many places livestock graze on the same lands used to produce crops of water, wood, and wildlife. In other parts of the forest there are excellent opportunities for outdoor recreation. Multiple Use means balancing the several uses of the forest family.
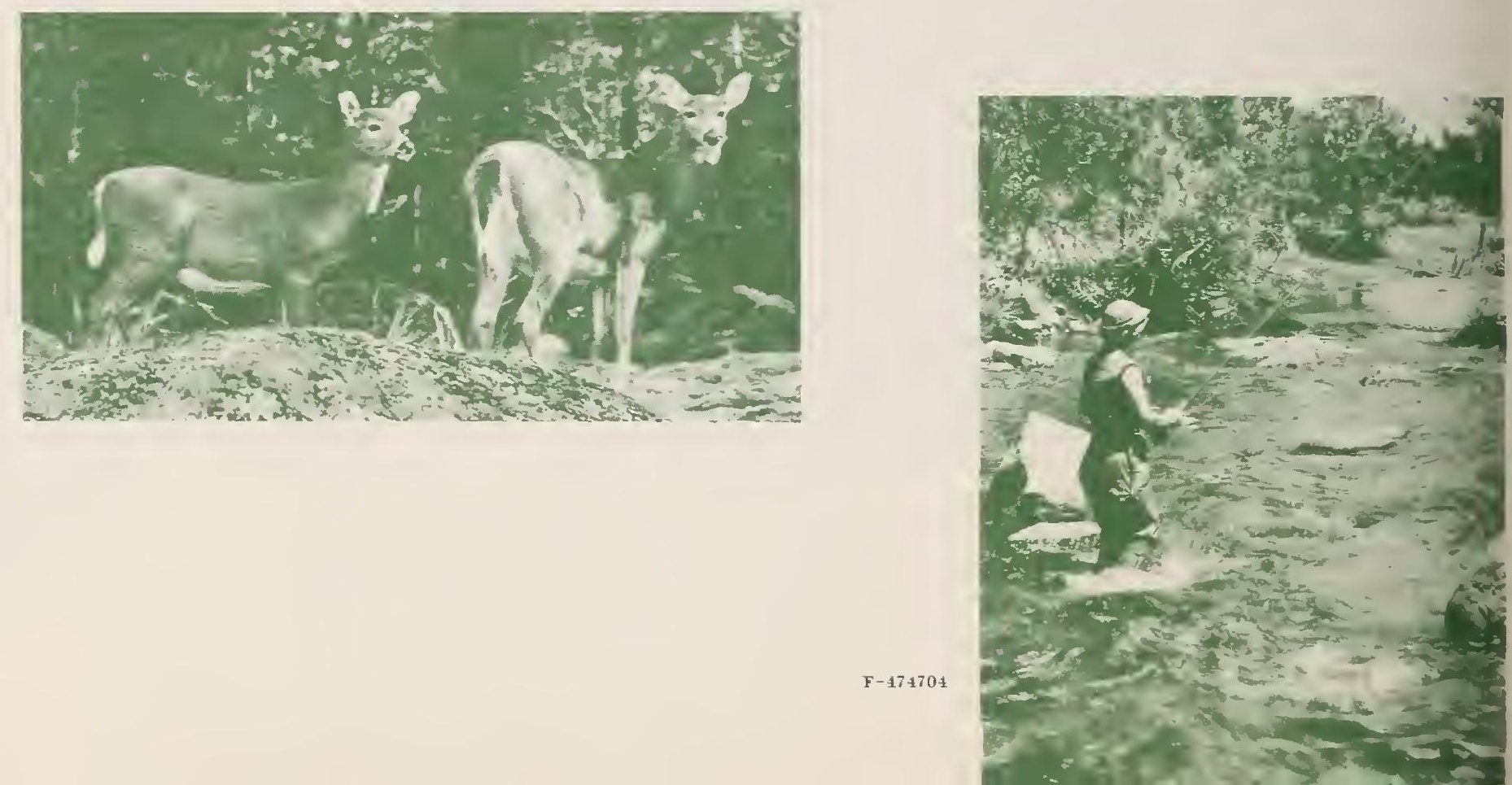


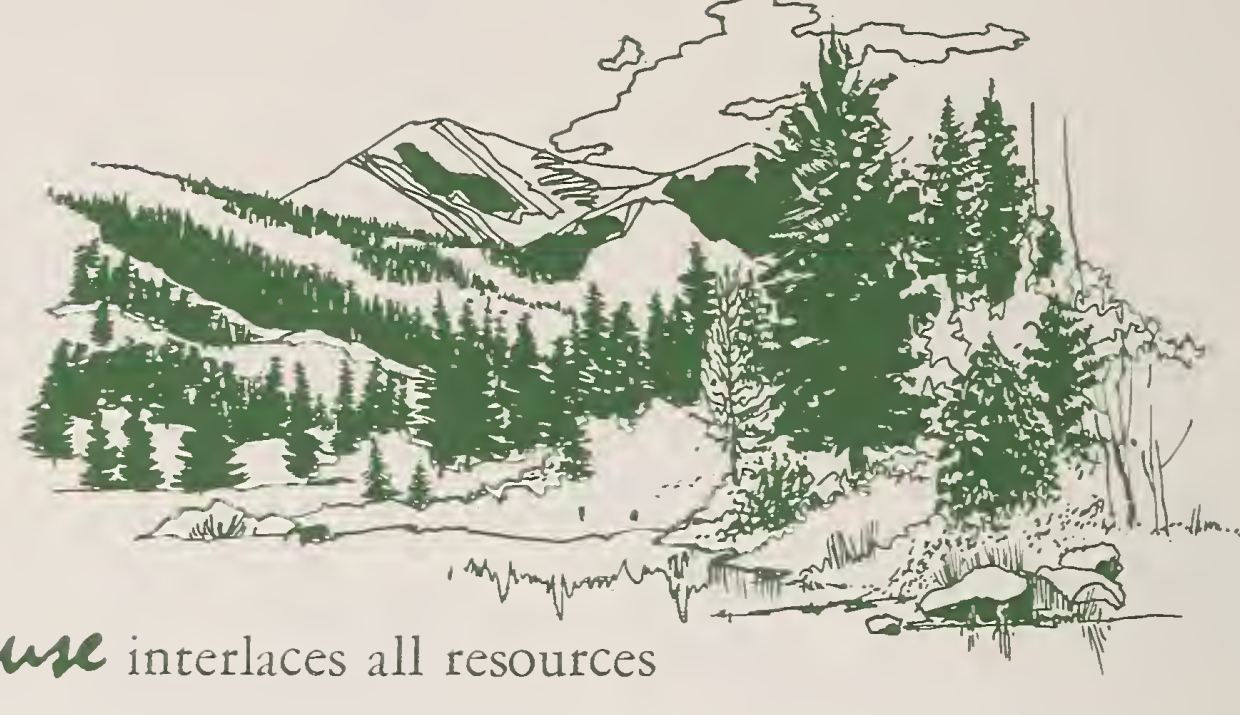

On the National Forests, timber is grown and harvested by methods which benefit other members of the forest family. For instance, on an area considered highly valuable for timber production, the trees are cut in such a way as to protect the soil, water, wildlife habitat, and other forest resources and to regenerate the forest. Multiple Use embraces timber and water, forage and wildlife, public campgrounds and wilderness. Minerals also have a place in this picture. Every effort is made to integrate the exploration and development of these nonrenewable resources with the management of the renewable surface resources. 


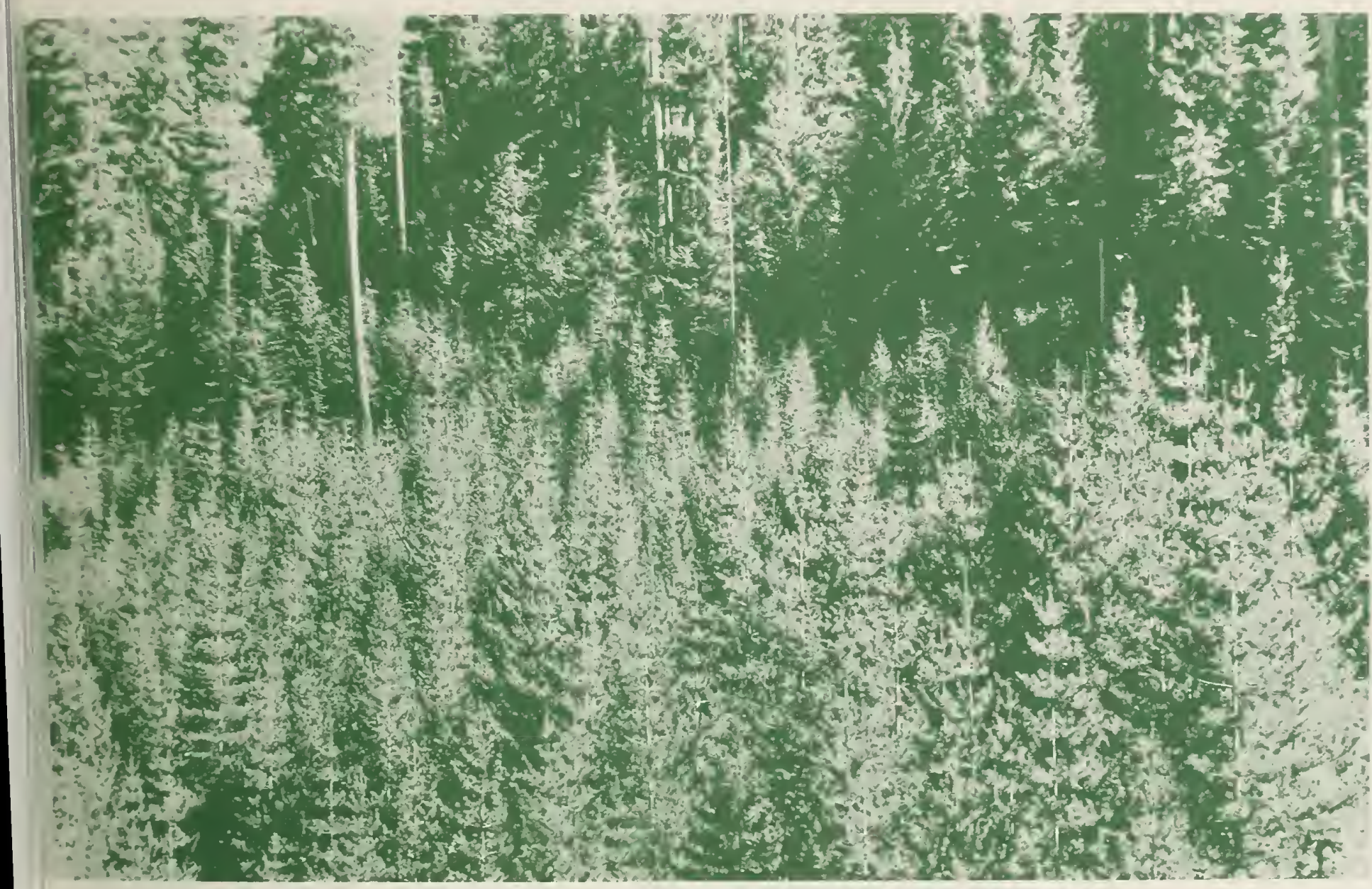

Timber for the future-young

pines replace harvested trees. F-351759 


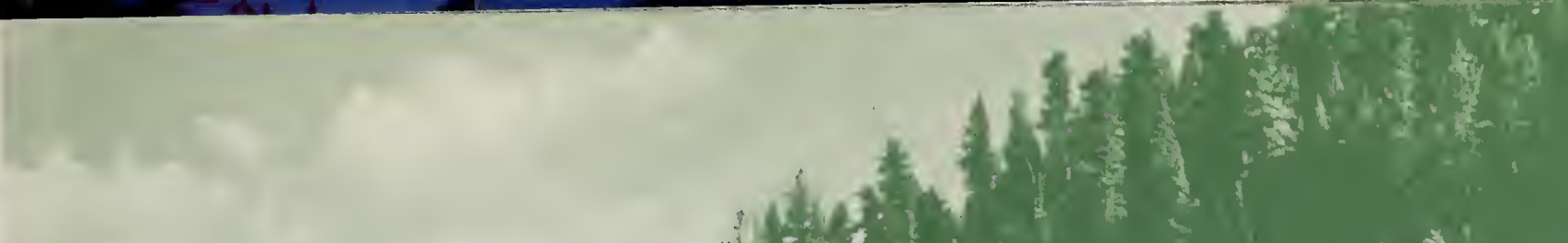

(1)

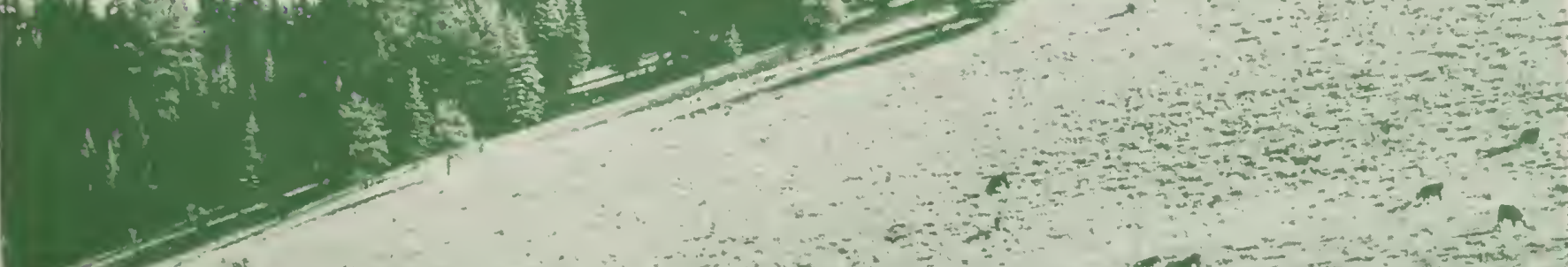

1.

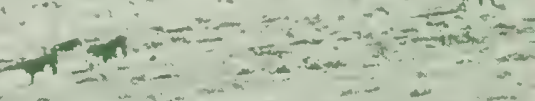

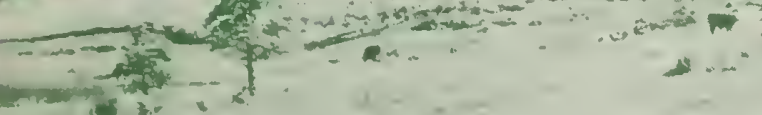

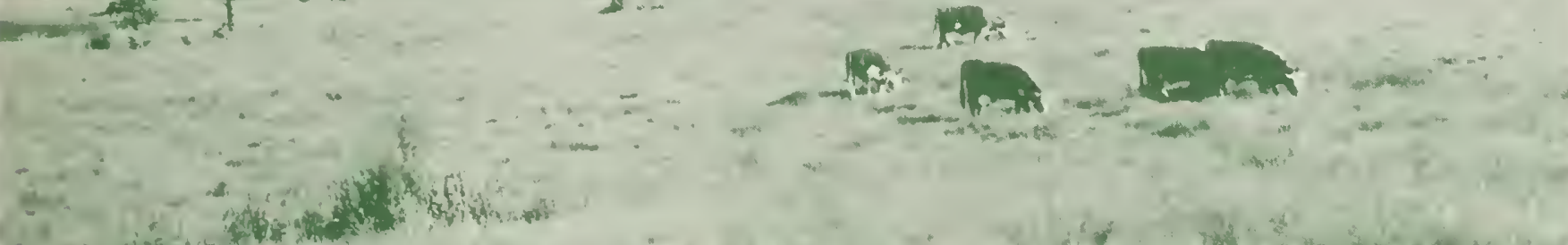

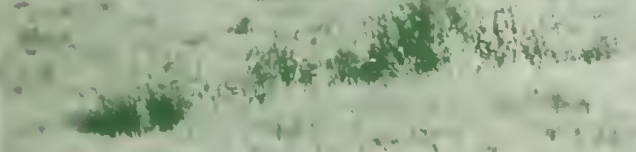

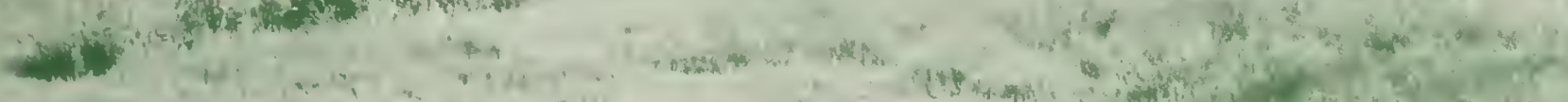

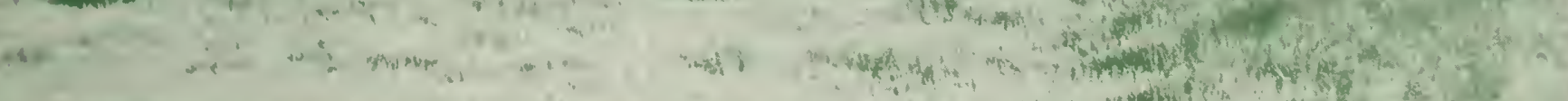

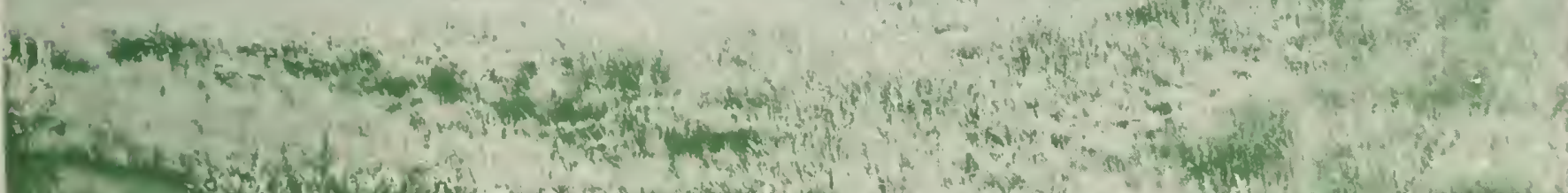

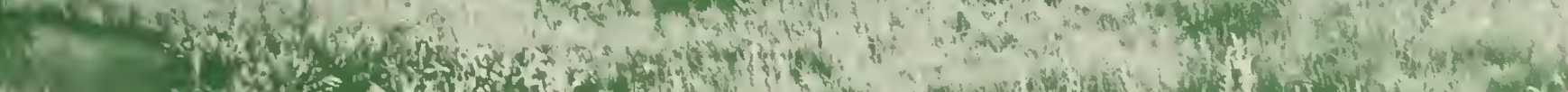

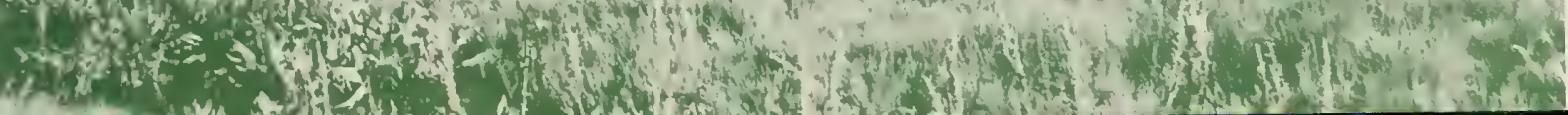

Grazing is an important National Forest use.

F- 487849 


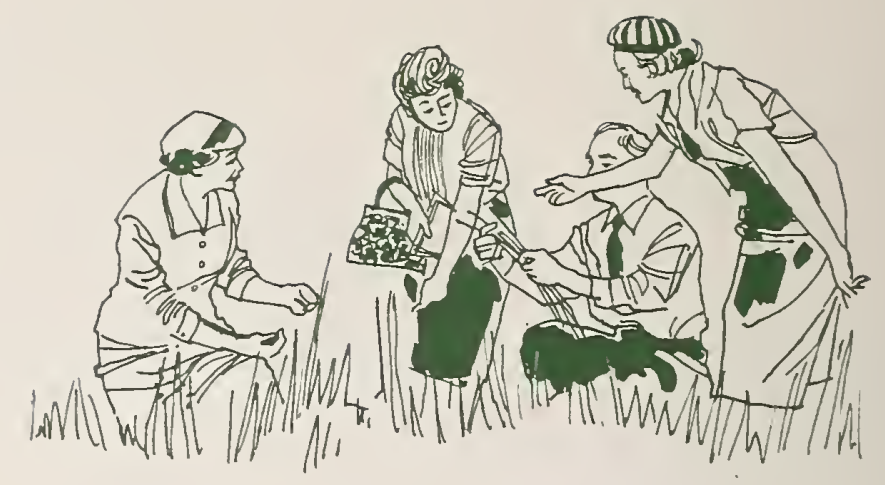

\section{multiple use is flexible use}

A logged-over area of National Forest land often provides excellent hunting. Wildlife habitat is generally improved by cutting timber, because the best game food and cover grows in open areas and not in deep forest. In harvesting National Forest timber, trees are left standing along streambanks to prevent erosion and provide shade to keep the water cool and healthful for fish. Hunting and fishing have created billion dollar industries and are therefore quite important to the economy of America, in addition to providing recreation. 


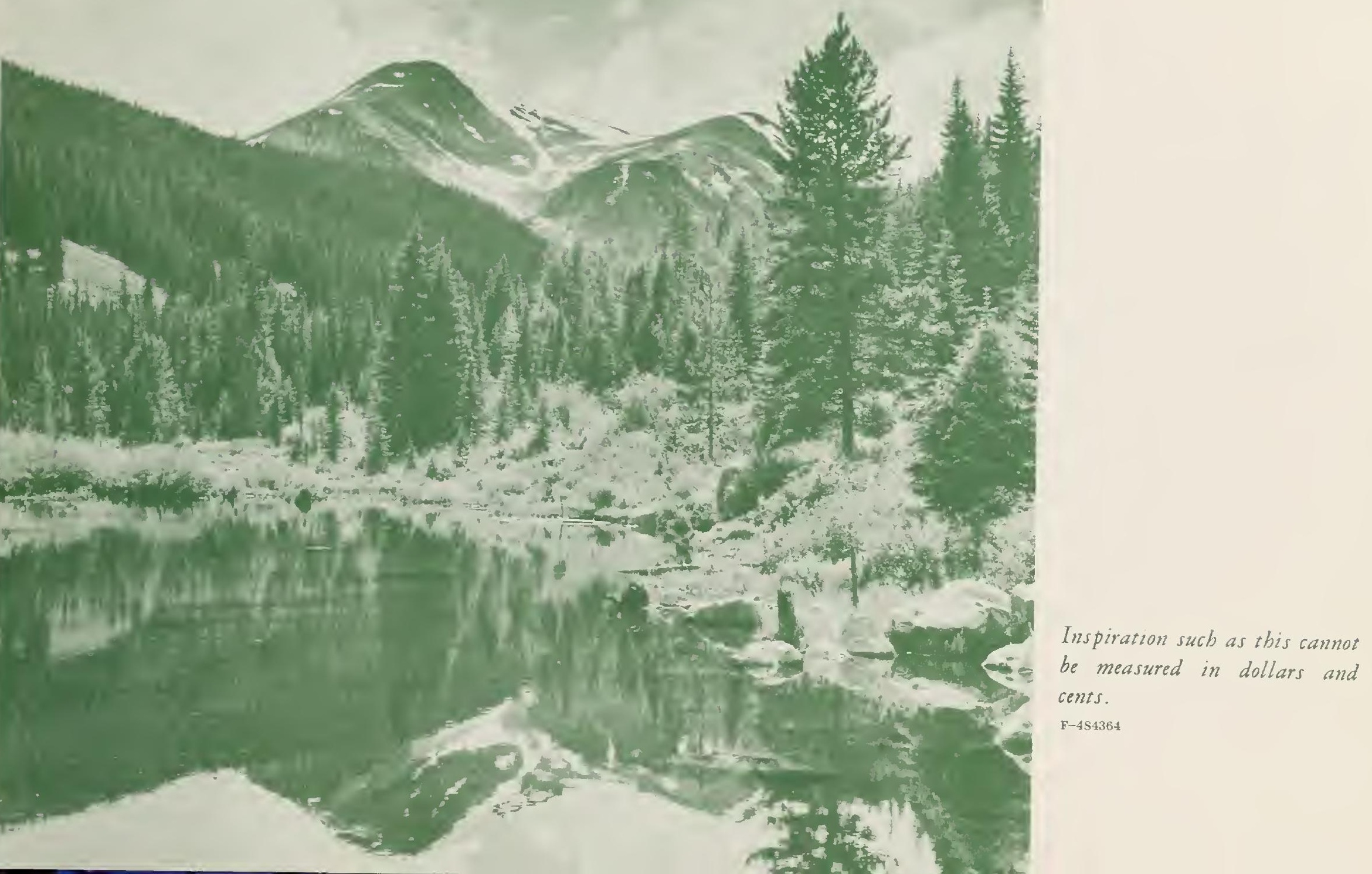




\section{multiple use management is often complex}

The National Forests serve many people who have many different interests in using these public properties. When competition arises, the problem is studied and resolved-use by use-by the National Forest managers in a manner that considers the best interests of both the forest users and the forest. Painstaking, carefully planned research is carried on to furnish the right answers. Multiple Use requires continuous planning, work, and attention.

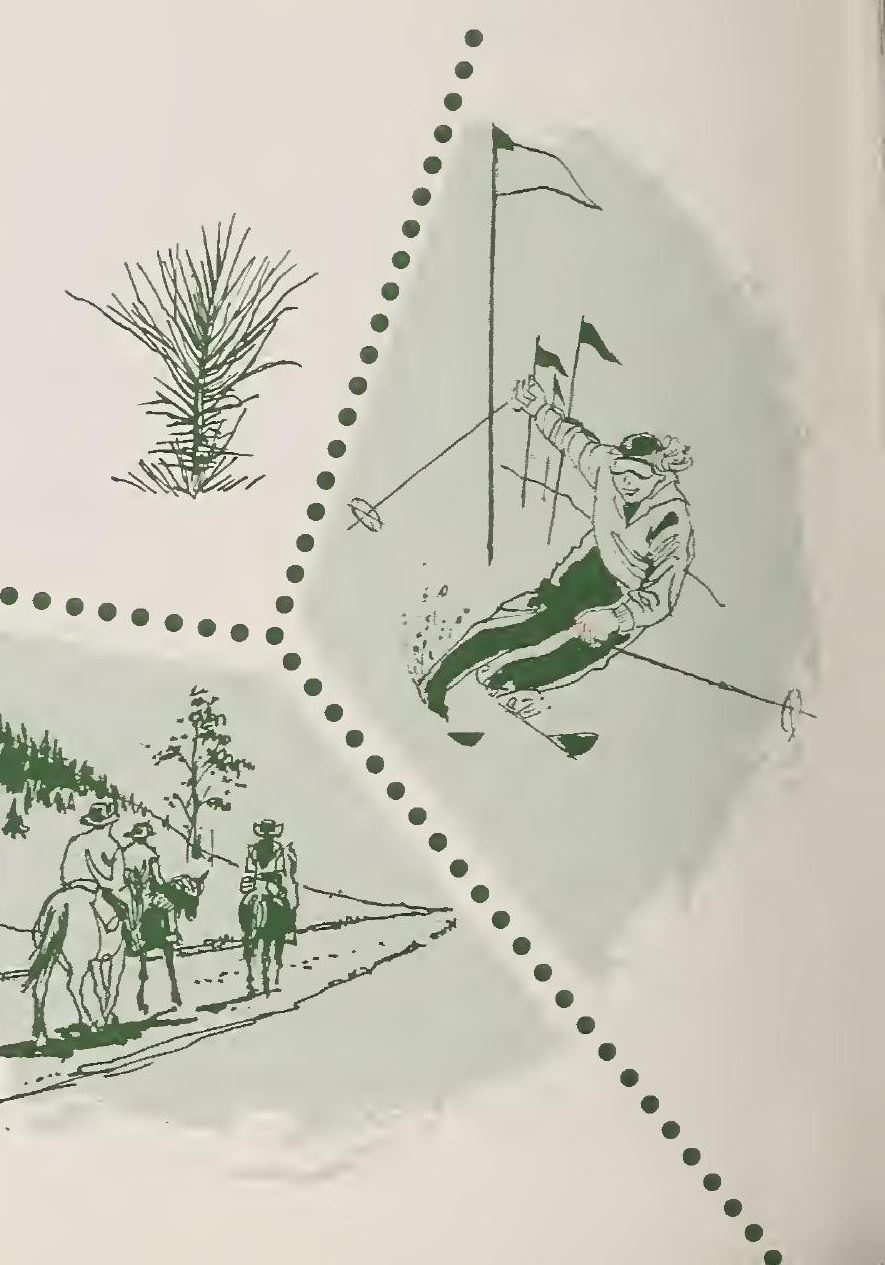




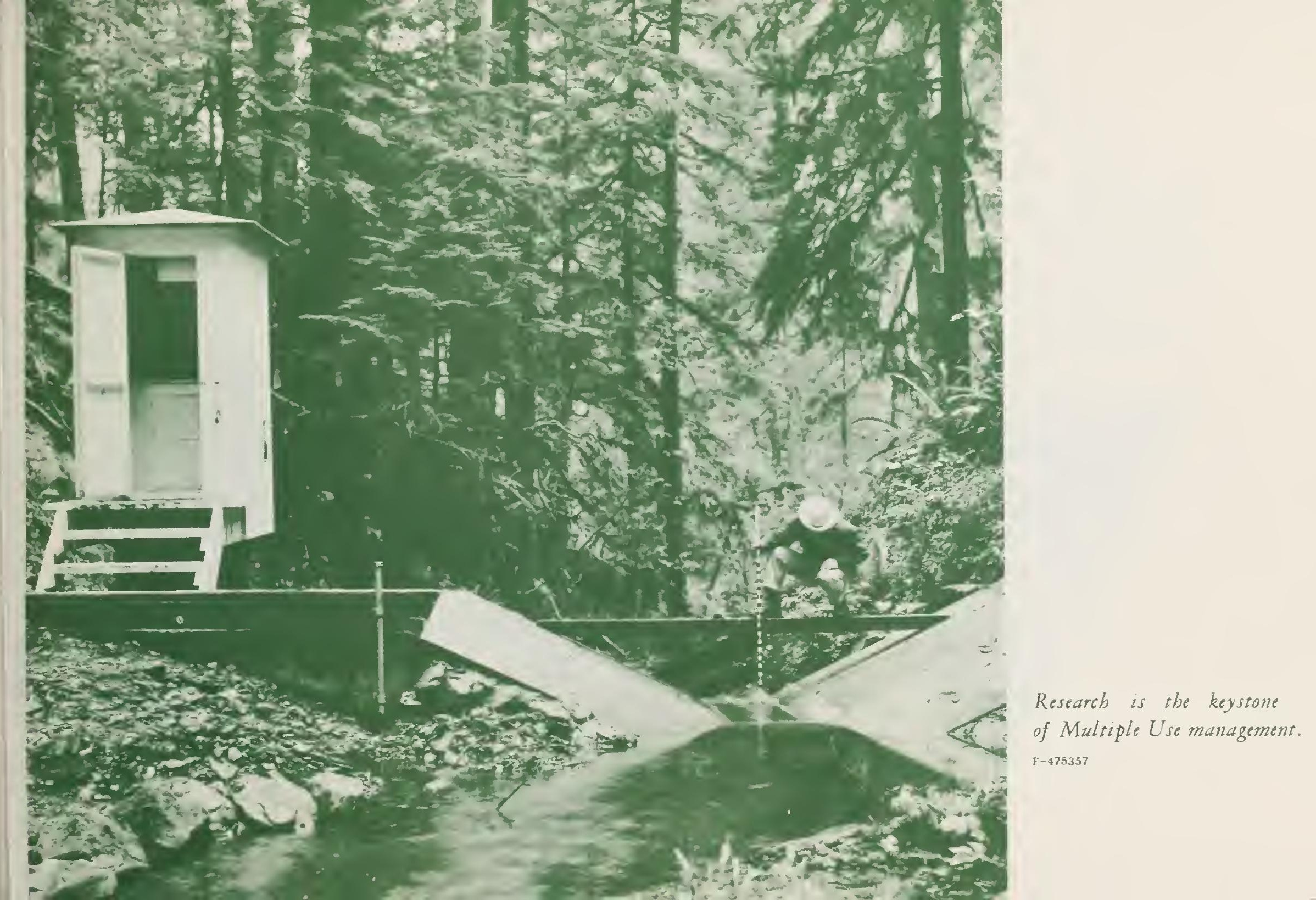


In the final analysis, Multiple Use . . . or many uses . . . is good land management which has broad application and significance. The goal of Multiple Use is to provide the greatest good to the greatest number of people in the long run, which means serving the best interests of all who use and enjoy the National Forests. The National Forest family - water, timber, forage, wildlife, and outdoor recreation-serves the families of America.

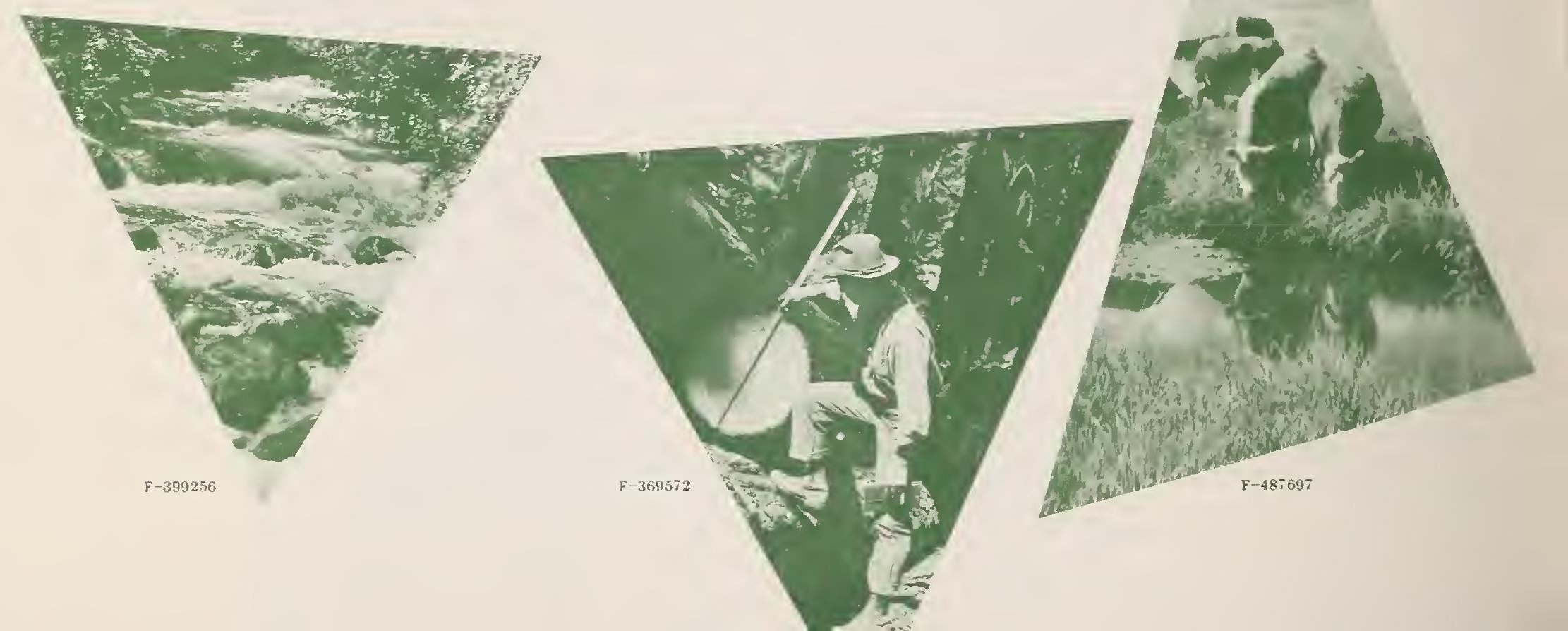




$$
* \mathbf{2}
$$




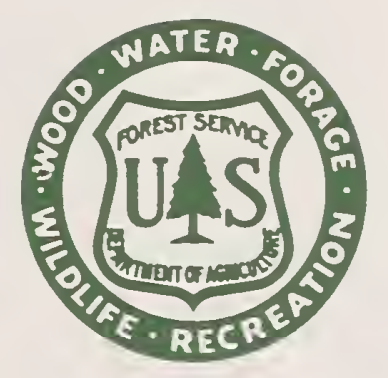

